\title{
Partial Jacobsen syndrome phenotype in a patient with a de novo frameshift mutation in the ETS1 transcription factor
}

\author{
Eva Tootleman, ${ }^{1}$ Barbara Malamut, ${ }^{2}$ Natacha Akshoomoff, ${ }^{3}$ Sarah N. Mattson, ${ }^{4}$ \\ Hal M. Hoffman, ${ }^{5}$ Marilyn C. Jones, ${ }^{5}$ Beth Printz, ${ }^{5}$ Sergey A. Shiryaev, ${ }^{6}$ \\ and Paul Grossfeld ${ }^{5}$ \\ ${ }^{1}$ Columbia Biosciences Corporation, Columbia, Maryland 21703, USA; ${ }^{2}$ Private Practice, Bryn Mawr, \\ Pennsylvania 19010, USA; ${ }^{3}$ Department of Psychiatry, UCSD School of Medicine, La Jolla, California 92093, \\ USA; ${ }^{4}$ Department of Psychology, San Diego State University, San Diego, California 92182, USA; ${ }^{5}$ Department \\ of Pediatrics, UCSD School of Medicine, La Jolla, California 92093, USA; ${ }^{6}$ Sanford Burnham Prebys Medical \\ Discover Institute, La Jolla, California 92037, USA
}

Corresponding author: pgrossfeld@ucsd.edu

(c) 2019 Tootleman et al. This article is distributed under the terms of the Creative Commons Attribution-NonCommercial License, which permits reuse and redistribution, except for commercial purposes, provided that the original author and source are credited.

Ontology term: hypoplastic left heart

Published by Cold Spring Harbor Laboratory Press

doi:10.1101/mcs.a004010
Abstract Jacobsen syndrome (OMIM \#147791) is a rare contiguous gene disorder caused by deletions in distal 11q. The clinical phenotype is variable and can include dysmorphic features, varying degrees of intellectual disability, behavioral problems including autism and attention deficit hyperactivity disorder, congenital heart defects, structural kidney defects, genitourinary problems, immunodeficiency, and a bleeding disorder due to impaired platelet production and function. Previous studies combining both human and animal systems have implicated several disease-causing genes in distal $11 q$ that contribute to the Jacobsen syndrome phenotype. One gene, ETS1, has been implicated in causing congenital heart defects, structural kidney defects, and immunodeficiency. We performed a comprehensive phenotypic analysis on a patient with congenital heart disease previously found to have a de novo frameshift mutation in ETS1, resulting in the loss of the DNA-binding domain of the protein. Our results suggest that loss of Ets1 causes a "partial Jacobsen syndrome phenotype" including congenital heart disease, facial dysmorphism, intellectual disability, and attention deficit hyperactivity disorder.

\section{INTRODUCTION}

Congenital heart defects are the most common human birth defect, occurring in $\sim 0.7 \%$ of all newborn infants (Ferencz 1989). Although most cases are thought to be due to a genetic etiology, a specific genetic cause has been identified in only a small subset of cases. Recent advances in genome-wide analyses are accelerating gene discovery for human diseases, including congenital heart disease (Glessner et al. 2014).

Jacobsen syndrome is a rare chromosomal disorder caused by deletions at the end of the long arm of Chromosome 11 (Jacobsen et al. 1973). About one-half of all people with Jacobsen syndrome have congenital heart defects, including one of the highest frequencies of hypoplastic left heart syndrome (Grossfeld et al. 2004). In addition to congenital heart disease, people with Jacobsen syndrome are at risk for numerous other problems including intellectual disability, behavioral problems including autism and attention deficit hyperactivity disorder, and immunodeficiency. We have previously identified the Ets1 transcription factor 
COLD SPRING HARBOR Molecular Case Studies
An ETS1 mutation and partial Jacobsen phenotype as a strong candidate gene for causing congenital heart defects in Jacobsen syndrome (Ye et al. 2010). In this report we perform a comprehensive phenotypic assessment on a patient with complex congenital heart disease who was found to have a de novo frameshift mutation in the ETS1 gene (Glessner et al. 2014).

\section{RESULTS}

\section{Clinical Presentation and Family History}

The patient is the full-term (38 wk gestation) male product of an uncomplicated pregnancy, born by normal spontaneous vaginal delivery, with a birth weight of $3.24 \mathrm{~kg}$ (41 st percentile), a length of $50.8 \mathrm{~cm}$ (68th percentile), and occipitofrontal circumference $33 \mathrm{~cm}$ (13th percentile). There was a nuchal cord, which was reduced without difficulty. Apgar scores were 7, 7, and 8 at 1, 5, and $10 \mathrm{~min}$, respectively. At $10 \mathrm{~h}$ of life, he was noted to be cyanotic and transferred to the neonatal intensive care unit. An echocardiogram was performed that revealed complex congenital heart disease, specifically double outlet right ventricle, unbalanced atrioventricular canal with a hypoplastic left-sided atrioventricular valve, bilateral superior vena cava, and a hypoplastic left ventricle. A renal ultrasound demonstrated normal kidney and urinary tract structure. He was discharged home on day of life 5, not on any cardiac medications. At age $5 \mathrm{wk}$, he underwent pulmonary artery banding and surgical ligation of a patent ductus arteriosus. At $18 \mathrm{mo}$, he underwent a "classic" Fontan procedure. At age $20 \mathrm{yr}$, he developed symptoms of congestive heart failure, requiring initially intravenous milrinone. He was subsequently transitioned to oral anticongestive including carvedilol, digoxin, enalapril, lasix, and warfarin. Starting at age 24, he had several recurrent skin infections over an 18-mo period of time, but no history of life-threatening or abnormally frequent infections. Because of some transient lapses of memory, a brain MRI was performed at age $24 \mathrm{yr}$, which demonstrated small areas of probable encephalomalacia in the bilateral frontal and right temporal lobes with accompanying volume loss, advanced for patient's age. An EEG was normal. The patient has not had any seizures.

At age $26 \mathrm{yr}$, he underwent a comprehensive dysmorphology evaluation, which revealed the following: height, $173 \mathrm{~cm}$ (33rd percentile); weight, $106 \mathrm{~kg}$; occipitofrontal circumference, $53 \mathrm{~cm}$ (<3rd percentile); and body mass index, $35.48 \mathrm{~kg} / \mathrm{m}^{2}$. Abnormal findings include mild microcephaly, bilateral ptosis $(R>L)$, downslanting palpebral fissures $(R>L)$, a low posterior hairline, and mild fifth clinodactyly. He also underwent an immune function evaluation, which revealed mildly decreased total B-cell numbers of 82 cells $/ \mu \mathrm{L}(91-409)$, as well as reduced naive $B$ cells and mature class-switched and non-class-switched memory $B$ cells. However, immunoglobulin levels and antibody responses to vaccines were normal as were T-cell, natural-killer-cell, and neutrophil counts.

\section{Developmental/Behavioral/Psychiatric History}

At age $6 \mathrm{mo}$, he was evaluated for early intervention, because of delays in fine and gross motor development, and found eligible for services. Early developmental milestones were delayed: sitting at $7 \mathrm{mo}$ and walking at $16 \mathrm{mo}$. At $20 \mathrm{mo}$, he started speech therapy for a feeding disorder, a neuromotor speech disorder, and receptive/expressive language delays. By 30 mo, he was speaking clearly in full sentences and eating a wider range of solid foods. He continued to have delays in pragmatic-language, perceptual/fine-motor, social-interaction, and problem-solving skills. He also exhibited impulsive and perseverative behaviors. He then received 2 yr of special education preschool services. He was diagnosed with attention deficit hyperactivity disorder at age 5 yr by a child psychiatrist. Behavioral and social difficulties continued, and at 7 yr 10 mo, he was prescribed stimulant medication. He received special 
COLD SPRING HARBOR Molecular Case Studies
An ETS1 mutation and partial Jacobsen phenotype education services throughout elementary school to improve attention and fine-motor skills, as well as private occupational therapy services. He had a support aide in middle school to help with focus and to ease transitions. He was very oppositional throughout puberty. In middle school, he received support in math and language arts, and his grades were always within average range. Beginning in 10th grade, he attended a private high school for special needs children, benefited from the supportive environment, and graduated first in a class of 16 students.

At age 19, he entered a supported independent living program for young adults with disabilities. He did well there, working on skills including banking, budgeting, cooking, and shopping, and working in a day-care setting for young disabled children. A neuropsychological evaluation indicated that he had strong verbal memory and language skills but weakness in visual-spatial-based tasks, slow processing speed, and attentional difficulty. He had difficulty with executive functioning, especially organizing and prioritizing.

He underwent a battery of standardized testing at age $24 \mathrm{yr}$ (Tables 1 and 2). He demonstrated core verbal intellectual skills in the high average range, auditory working memory in the average range, and visual-spatial perceptual skills and visual motor processing speed within the low average range. Reading comprehension was average, but math skills were in the borderline range. Verbal memory and learning were stronger than his average to impaired visual spatial memory. Attention was average while taking Focalin. He demonstrated inadequate monitoring, planning, and organizational skills and variable cognitive flexibility. $\mathrm{He}$ also had difficulty shifting between tasks, rigid adherence to plans or routines, poor selfinitiation, and poor emotional control. Bilateral fine motor dexterity and visually guided motor movements were impaired and manifested by sloppy handwriting and impaired figure copying.

Table 1. Results of neuropsychological functioning

\begin{tabular}{|c|c|c|c|}
\hline Domain & Test & Subtest & Percentile \\
\hline \multirow[t]{5}{*}{ Intellectual } & WAIS-IV & FSIQ & 34 \\
\hline & & $\mathrm{VCl}$ & 82 \\
\hline & & PRI & 14 \\
\hline & & WMI & 42 \\
\hline & & PSI & 10 \\
\hline \multirow[t]{10}{*}{ Memory } & WMS-IV & LM I (Immediate) & 50 \\
\hline & & LM II (Delay) & 9 \\
\hline & & Designs I (Immediate) & 9 \\
\hline & & Designs II (Delay) & 37 \\
\hline & CVLT-II & Total learning & 47 \\
\hline & & List B & 7 \\
\hline & & SD recall & 32 \\
\hline & & Delay recall & 16 \\
\hline & RCFT & Immed & $\leq 1$ \\
\hline & & Delay & $<1$ \\
\hline \multirow[t]{2}{*}{ Figure copy } & Beery VMI & Copy & $\leq 1$ \\
\hline & RCFT & Copy & $\leq 1$ \\
\hline \multirow[t]{2}{*}{ Visual motor } & Purdue Pegboard & Dominant right hand & $<0.1$ \\
\hline & & Nondominant left hand & $<0.1$ \\
\hline \multirow[t]{2}{*}{ Academic achievement } & WIAT-III & Numerical operations & 7 \\
\hline & WJ-III & Passage comprehension & 53 \\
\hline
\end{tabular}

(WAIS-IV) Wechsler Adult Intelligence Scale-Fourth Edition, (CVLT-II) California Verbal Learning Test-Second Edition, (RCFT) Rey-Osterrieth Complex Figure Test, (WMS-IV) Wechsler Memory Scale-Fourth Edition, (LM) Logical Memory and Designs subtests, (WIAT-III) Wechsler Individual Achievement Test-Third Edition, (WJ-III) Woodcock-Johnson III Tests of Achievement, and (Beery VMI) Beery Buktenica Developmental Test of Visual Motor Integration-Fifth Edition. 
Table 2. Behavior rating inventory of executive function (BRIEF)

\begin{tabular}{lcc}
\hline Scale & Self-report & Informant report (mother) \\
\hline Inhibit & 43 & $66^{\mathrm{a}}$ \\
Shift & 56 & $80^{\mathrm{a}}$ \\
Emotional control & 45 & $67^{\mathrm{a}}$ \\
Self-monitor & 50 & 58 \\
Behavioral Regulation Index (BRI) & 47 & $69^{\mathrm{a}}$ \\
Initiate & 47 & 54 \\
Working memory & 59 & 58 \\
Plan/organize & 49 & $65^{\mathrm{a}}$ \\
Task monitor & 45 & $69^{\mathrm{a}}$ \\
Organization of materials & 50 & 63 \\
Metacognition Index (MI) & 50 & 63 \\
General Executive Composite (GEC) & 49 & $67^{\mathrm{a}}$ \\
\hline
\end{tabular}

All scores presented as $T$-scores.

${ }^{\mathrm{a}} \mathrm{T}$-scores of 65 or higher represent areas of significant concern.

He also has a long-standing history of significant social impairments, including poor perception and initiation of social cues and gestures, and limited social-emotional reciprocity. He has difficulty with self-help and independent living skills. Currently, he is driving and working at a local drugstore.

\section{Genomic Analysis}

At age 20, as part of the Pediatric Cardiac Genomics Consortium the patient underwent whole-exome sequencing which revealed a de novo frameshift nonsense mutation (c.1044_1049delCAAGGAinsTT; resulting in a p.Lys349SerfsX2) in the ETS1 cardiac transcription factor. No disease-causing copy-number variations were identified in the patient. Targeted sequencing on the patient confirmed the original findings. His mother and father underwent targeted gene sequencing and were both found to not carry the mutation. The mutation causes a 20 -amino acid mutant sequence followed by a premature termination (Table 3; Fig. 1).

\begin{tabular}{|c|c|c|c|c|c|c|c|c|c|c|c|}
\hline Gene & $\begin{array}{l}\text { Chromo- } \\
\text { some }\end{array}$ & $\begin{array}{l}\text { HGVS DNA } \\
\text { reference }\end{array}$ & $\begin{array}{l}\text { HGVS } \\
\text { protein } \\
\text { reference }\end{array}$ & $\begin{array}{l}\text { Variant } \\
\text { type }\end{array}$ & $\begin{array}{l}\text { Predicted } \\
\text { effect } \\
\text { (substi- } \\
\text { tution, } \\
\text { deletion, } \\
\text { etc.) }\end{array}$ & $\begin{array}{c}\text { dbSNP/ } \\
\text { dbVar } \\
\text { ID }\end{array}$ & $\begin{array}{c}\text { Genotype } \\
\text { (hetero- } \\
\text { zygous/ } \\
\text { homo- } \\
\text { zygous) }\end{array}$ & $\begin{array}{c}\text { ClinVar } \\
\text { ID } \\
\text { (optional) }\end{array}$ & $\begin{array}{l}\text { Parent of } \\
\text { origin } \\
\text { (optional) }\end{array}$ & $\begin{array}{l}\text { Observed } \\
\text { effect (if } \\
\text { shown to } \\
\text { be different } \\
\text { from } \\
\text { predicted } \\
\text { effect) } \\
\text { (optional) }\end{array}$ & $\begin{array}{l}\text { Comments } \\
\text { (optional) }\end{array}$ \\
\hline ETS1 & 11 & $\begin{array}{l}\text { c.1044_1049 } \\
\text { deICAAGGA } \\
\text { insTT }\end{array}$ & p.Lys349SerfsX2 & $\begin{array}{l}\text { Loss of } \\
\quad \text { function }\end{array}$ & Del/ins & $\begin{array}{l}\text { PCGC ID } \\
1-01334\end{array}$ & Het & & De novo & & $\begin{array}{l}\text { This insertion/ } \\
\text { deletion } \\
\text { causes a } \\
\text { premature } \\
\text { termination } \\
\text { that likely } \\
\text { results in a } \\
\text { loss of } \\
\text { function of } \\
\text { that copy of } \\
\text { the gene. }\end{array}$ \\
\hline
\end{tabular}


A Domains composition in ETS1 wt

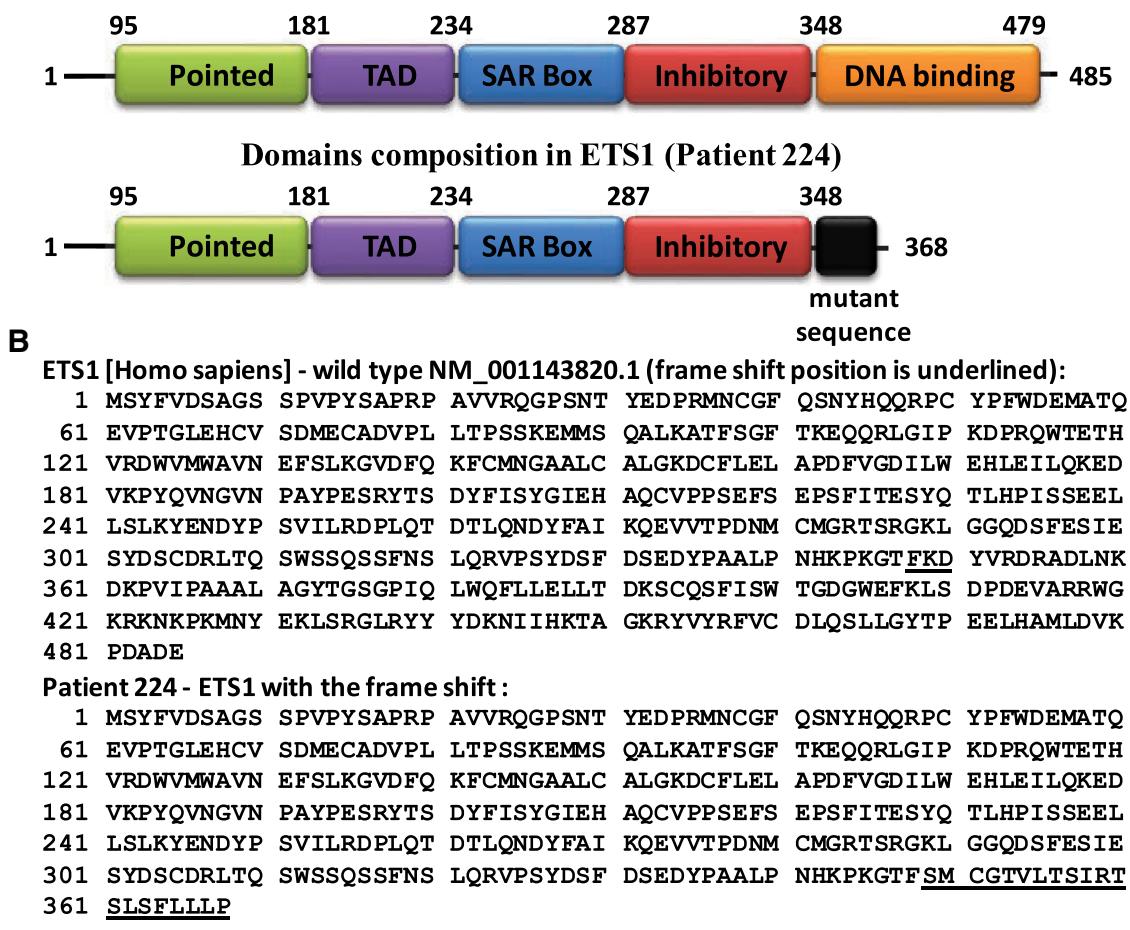

Figure 1. ETS1 wild-type protein sequence and the same protein sequence after frameshift (Pt). (A) Structure of human ETS1 protein with previously defined domains. The pointed domain is involved in binding of ERK kinases to ETS1; the TAD domain is responsible for transactivation; the SAR domain is proposed to interact with SAR-interacting protein (SIP); the inhibitory domain suppresses ETS1 binding to DNA; and the DNA-binding domain (or ETS domain) is responsible for recognition and binding to the specific DNA sequences. (B) Amino acid sequence of wild-type human ETS1 protein and amino acid sequence of c.1044_1049delCAAGGAinsTT variant (patient) with additional mutant sequence (20-amino acids long—underlined).

\section{DISCUSSION}

In this report we describe the clinical phenotype of a patient carrying a de novo frameshift mutation in the ETS1 transcription factor, a gene that has been implicated in causing several of the clinical problems that occur in Jacobsen syndrome including congenital heart defects, cognitive and behavioral problems, immunodeficiency, structural kidney defects, and dysmorphic features. Previous studies have indicated that ETS1 is expressed in the neural crest, the central nervous system, and the endocardium of the heart in the developing mouse embryo (Ye et al. 2010). Consequently, the clinical phenotype manifested by this patient is consistent with the murine gene expression pattern.

The patient has mild craniofacial features that are consistent with a neural crest cell defect. In ETS1 knockout mice, loss of ETS1 is thought to cause a neural crest cell migration defect (Gao et al. 2010), resulting in decreased neural crest cells reaching their final destination. In the heart, loss of ETS1 causes, most commonly, isolated (perimembranous) or more complex (double outlet right ventricle) ventricular septal defects and, less frequently, a hypoplastic left ventricle (Grossfeld et al. 2004; Ye et al. 2010). The patient has a complex congenital heart defect which may be due to a combination of loss of function in both the cardiac neural crest and the endocardium, two lineages that are essential for normal cardiac development. 
COLD SPRING HARBOR Molecular Case Studies
An ETS1 mutation and partial Jacobsen phenotype
Many patients with Jacobsen syndrome present with recurrent infections. More than $50 \%$ of our cohort reported frequent upper respiratory infections, but we did not detect evidence of significant immune deficiency in a small subgroup of patients screened (Grossfeld et al. 2004). Since that time several Jacobsen syndrome patients have undergone more comprehensive immune evaluations and a variety of abnormalities have been reported, including low levels of one or more immunoglobulin isotypes (lgG, IgA, lgM) or subclasses, poor antibody responses to vaccines (i.e., pneumococcal), low numbers of one or more lymphocyte type $(B, T, N K)$ or subtypes, and inadequate $T$-cell responses to mitogens or antigen, establishing Jacobsen as a syndromic combined immunodeficiency with variable presentation similar to common variable immune deficiency (Dalm et al. 2015; Blazina et al. 2016). Loss of ETS1 has been proposed as the genetic basis for immune cell dysfunction as observed in multiple mouse studies using knockout or hypomorphic mouse models (Russell and GarrettSinha 2010; Garrett-Sinha 2013). However, heterozygous mice, which would be more relevant for our patient and others with Jacobsen syndrome, were often normal, not studied, nor even used as controls. At the time of this study, our patient had only mildly low total B-cell numbers, but an otherwise unremarkable immune workup consistent with his lack of significant infections. Therefore, we cannot confirm that loss of ETS1 is the cause of immune abnormalities seen in Jacobsen syndrome patients. We will continue to follow our patient, as it is possible that he may develop additional infections and immune abnormalities in the future, as observed in many patients with a common variable immune deficiency phenotype.

The patient demonstrated weaknesses in a range of cognitive and adaptive behavior skills and behavioral problems, including attention deficit hyperactivity disorder. Although little is currently known about the neurobehavioral profile of Jacobsen syndrome, multiple reports support developmental delays, including intellectual disability, and significant behavioral problems. Emerging evidence suggests that attention deficit hyperactivity disorder is a common diagnosis in this population (Mattson S, unpubl. data), as are features of autism spectrum disorder (Akshoomoff et al. 2015). This patient's behavioral profile is consistent with these reports, and the details provided herein add to the limited literature on the cognitive and behavioral features seen in Jacobsen syndrome, specifically due to loss of ETS1. The pattern of lateralized function, with greater impact on right hemisphere function, has not been reported and may not be related to Jacobsen syndrome. Although unlikely, it is possible that at least some of these problems could be due to being born with a nuchal cord. However, the patient had stable Apgar scores and did not have any neurologic deficits or seizures in the neonatal period, suggesting that he did not suffer a hypoxic-ischemic brain injury at birth.

To our knowledge, the study by Glessner et al. is the first to report a disease-causing mutation identified by whole-exome sequencing in a patient with congenital heart disease, indicating that point mutations in ETS1 are rare in patients with congenital heart disease (e.g., Sifrim et al. 2016; Jin et al. 2017). However, deletions spanning the ETS1 gene are more common and, for example, account for $\sim 1 \%$ of all cases of hypoplastic left heart syndrome (Grossfeld P, unpubl. data).

In summary, this patient carries a de novo loss of function mutation in ETS1 in association with multiple problems that occur in Jacobsen syndrome, providing further support for ETS1 as a major contributor to the clinical phenotype that occurs in the syndrome (Table 4). A recent study described a high frequency of brain anomalies in association with congenital heart defects, suggesting a common genetic etiology for these problems, as is likely the case in the patient described in this report (Homsy et al. 2015). In the future, routine genome sequencing is likely to identify more patients with Jacobsen syndrome phenotypes and mutations in ETS1 and/or the gene regulatory network involving ETS1. This should further establish the role of ETS1 in causing disease and advance our understanding of the pathogenesis of several of the clinical features that occur in Jacobsen syndrome. 


\begin{tabular}{llc}
\hline \multicolumn{2}{l}{ Table 4. Clinical phenotypes in the patient and frequency in Jacobsen syndrome (JS) } \\
\hline \multicolumn{1}{l}{ System/defect } & \multicolumn{1}{c}{ Patient } & Present in JS \\
\hline Congenital heart disease & Complex single ventricle & Yes (54\%) \\
ADHD & Yes & Yes $(41 \%)^{\mathrm{a}}$ \\
Intellectual disability & Yes & Yes $(>95 \%)^{a}$ \\
Abnormal brain MRI & Yes & Yes $(51 \%)^{b}$ \\
Immunodeficiency & Decreased B cells & Yes $(83 \%)^{\mathrm{c}}$ \\
Structural kidney defects & No & Yes $(8 \%)^{\mathrm{b}}$ \\
Craniofacial defects & Ptosis, microcephaly & Yes $(>95 \%)^{\mathrm{b}}$ \\
& Downslanting palpebral & \\
\hline
\end{tabular}

aBased on Direct Behavioral Rating Scale, $n=86$ (Mattson S, unpubl data, 2019).

${ }^{\mathrm{b}}$ From Grossfeld et al. 2004.

cFrom Dalm et al. 2015.

\section{METHODS}

Whole-exome sequencing was performed as described previously by Glessner et al. (2014) as part of the Pediatric Cardiac Genomics Consortium Bench to Bassinet project. Average sequencing coverage was $60 \times$. IRB-approved consent was obtained from the proband and his parents. Targeted sequencing was performed on the patient and his parents by GeneDx. Specifically, using genomic DNA from the submitted specimen, the relevant portion of the requested gene was PCR amplified and capillary (Sanger) sequencing was performed. Bi-directional sequence was assembled, aligned to reference gene sequences based on human genome build GRCh37/UCSC hg19 and analyzed for the known sequence variant. Sequence alterations were reported according to the Human Genome Variation Society (HGVS) nomenclature guidelines.

\section{ADDITIONAL INFORMATION}

\section{Data Deposition and Access}

The PCGC patient ID is 1-01334. The variant was submitted to ClinVar (https://www.ncbi.nih .nlm.gov/clinvar/) and can be found under accession number SCV000900034.1. The raw sequencing data was not deposited because patient consent was not obtained.

\section{Ethics Statement}

Whole-exome sequencing was performed as described previously by Glessner et al. (2014) as part of the Pediatric Cardiac Genomics Consortium Bench to Bassinet project. IRBapproved consent was obtained from the proband and his parents.

\section{Acknowledgments}

The authors would like to thank the Pediatric Cardiology Genomics Consortium for identifying and referring the patient. That project was supported by Award Number(s) UM1HL098147, UM1HL098123, U01HL098163, U01HL098153, UM1HL098162, and U01HL098188 from the National Heart, Lung, and Blood Institute. The content is solely the responsibility of the authors and does not necessarily represent the official views of 
Competing Interest Statement

The authors have declared no competing interest.

Received January 29, 2019; accepted in revised form March 28, 2019. the National Heart, Lung, and Blood Institute nor the National Institutes of Health. The authors would also like to thank the patient and his family for their cooperation in the study.

\section{Author Contributions}

E.T. is the mother of the patient. She provided all of the past medical and developmental history and assisted with the writing of the manuscript. B.M. performed the neurocognitive assessments and testing on the patient at age 26 and assisted in the writing of the manuscript. N.A. analyzed the neurodevelopmental data and assisted in the writing of the manuscript. S.N.M. analyzed the neurodevelopmental data and assisted in the writing of the manuscript. H.M.H. oversaw the immune function testing and assisted in the preparation of the manuscript. M.C.J. performed the comprehensive dysmorphology evaluation of the patient and assisted in the writing of the manuscript. B.P. performed the initial cardiac evaluations of the patient and assisted in the writing of the manuscript. S.A.S. performed the bioinformatics analysis of the patient's mutation, generated the figure, and assisted in the writing of the manuscript. P.G. conceived the idea of the manuscript, coordinated all of the data collection and analysis, and oversaw the writing of the manuscript.

\section{REFERENCES}

Akshoomoff N, Mattson SN, Grossfeld PD. 2015. Evidence for autism spectrum disorder in Jacobsen syndrome: identification of a candidate gene in distal 11q. Genet Med 17: 143-148.

Blazina Š, Ihan A, Lovrečić L, Hovnik T. 2016. 11q terminal deletion and combined immunodeficiency (Jacobsen syndrome): case report and literature review on immunodeficiency in Jacobsen syndrome. Am J Med Genet A 170: 3237-3240. doi:10.1002/ajmg.a.37859

Dalm VA, Driessen GJ, Barendregt BH, van Hagen PM, van der Burg M. 2015. The 11q terminal deletion disorder Jacobsen syndrome is a syndromic primary immunodeficiency. J Clin Immunol 35: 761-768. doi:10 $.1007 / \mathrm{s} 10875-015-0211-z$

Ferencz C. 1989. Origin of congenital heart disease: reflections on Maude Abbott's work. Can J Cardiol 5: 4-9.

Gao Z, Kim GH, Mackinnon AC, Flagg AE, Bassett B, Earley JU, Svensson EC. 2010. Ets1 is required for proper migration and differentiation of the cardiac neural crest. Development 137: 1543-1551. doi:10.1242/dev .047696

Garrett-Sinha LA. 2013. Review of Ets1 structure, function and roles in immunity. Cell Mol Life Sci 70: 33753390. doi:10.1007/s00018-012-1243-7

Glessner JT, Bick AG, Ito K, Homsy J, Rodriguez-Murillo L, Fromer M, Mazaika E, Vardarajan B, Italia M, Leipzig $\mathrm{J}$, et al. 2014. Increased frequency of de novo copy number variants in congenital heart disease by integrative analysis of single nucleotide polymorphism array and exome sequence data. Circ Res 115: 884-896. doi:10.1161/CIRCRESAHA.115.304458

Grossfeld PD, Mattina T, Lai Z, Favier R, Jones KL, Cotter F, Jones C. 2004. The terminal 11 q deletion disorder: a prospective study of 110 cases. Am J Med Genet 129A: 51-61. doi:10.1002/ajmg.a.30090

Homsy J, Zaidi S, Shen Y, Ware JS, Samocha KE, Karczewski KJ, DePalma SR, McKean D, Wakimoto H, Gorham $\mathrm{J}$, et al. 2015. De novo mutations in congenital heart disease with neurodevelopmental and other congenital anomalies. Science 350: 1262-1266. doi:10.1126/science.aac9396

Jacobsen P, Hauge M, Henningsen K, Hobolth N, Mikkelsen M, Philip J. 1973. An (11;21) translocation in four generations with chromosome 11 abnormalities in the offspring. Hum Hered 23: 568-585. doi:10.1159/ 000152624

Jin SC, Homsy J, Zaidi S, Lu Q, Morton S, DePalma SR, Zeng X, Qi H, Chang W, Sierant MC, et al. 2017. Contribution of rare inherited and de novo variants in 2,871 congenital heart disease probands. Nat Genet 49: 1593-1601. doi:10.1038/ng.3970

Russell L, Garrett-Sinha LA. 2010. Transcription factor Ets-1 in cytokine and chemokine gene regulation. Cytokine 51: 217-226. doi:10.1016/j.cyto.2010.03.006

Sifrim A, Hitz MP, Wilsdon A, Breckpot J, Al Turki SH, Thienpont B, McRae J, Fitzgerald TW, Singh T, Swaminathan GJ, et al. 2016. Distinct genetic architectures for syndromic and nonsyndromic congenital heart defects identified by exome sequencing. Nat Genet 48: 1060-1065. doi:10.1038/ng.3627

Ye M, Coldren C, Benson W, Goldmuntz E, Ostrowski M, Watson D, Perryman B, Grossfeld P. 2010. Deletion of ETS-1, a gene in the Jacobsen syndrome critical region, causes ventricular septal defects and abnormal ventricular morphology in mice. Hum Mol Genet 19: 648-656. doi:10.1093/hmg/ddp532 


\section{COLD SPRING HARBOR Molecular Case Studies}

\section{Partial Jacobsen syndrome phenotype in a patient with a de novo frameshift mutation in the ETS1 transcription factor}

Eva Tootleman, Barbara Malamut, Natacha Akshoomoff, et al.

Cold Spring Harb Mol Case Stud 2019, 5: a004010

Access the most recent version at doi: $10.1101 / \mathrm{mcs} . a 004010$

References This article cites 14 articles, 3 of which can be accessed free at: http://molecularcasestudies.cshlp.org/content/5/3/a004010.full.html\#ref-list-1

License This article is distributed under the terms of the Creative Commons Attribution-NonCommercial License, which permits reuse and redistribution, except for commercial purposes, provided that the original author and source are credited.

Email Alerting Receive free email alerts when new articles cite this article - sign up in the box at the Service top right corner of the article or click here. 